\title{
Building the Profession of Adult Education: The Case of the University of Botswana's Department of Adult Education
}

\author{
Oitshepile MmaB Modise \\ Department of Adult Education, University of Botswana, Gaborone, Botswana \\ Email: Modiseom@mopipi.ub.bw
}

Received 14 July 2015; accepted 27 December 2015; published 30 December 2015

Copyright (C) 2015 by author and Scientific Research Publishing Inc.

This work is licensed under the Creative Commons Attribution International License (CC BY). http://creativecommons.org/licenses/by/4.0/

(c) †) Open Access

\begin{abstract}
A study was carried out with former graduates of the University of Botswana, Department of Adult Education to explore the issues related to professionalisation of adult education careers in Botswana. An underlying goal was to explore the unique characteristics of the Department of Adult Education (DAE) at the University of Botswana. This study took a case study approach by focusing only on the Department of Adult Education graduates. Participants' involvement was solicited using purposive sampling. However, snowballing also was applied to help the researcher locate more former students. The methodology used was basically qualitative relying on the phenomenological paradigm. As the researcher was interested in perceptions, opinions and experience of participants as they were related to what constitutes professionalisation in the field of adult education as practised by the Department of Adult Education (DAE) at the University of Botswana. The findings indicate that adult educators acquire a set of "flexible" skills that would allow them to adapt to a changing employment situation and to develop new avenues for adult education in varied institutional settings. Stakeholders concurred that professional associations are presently weak in Botswana and made suggestions for more vigorous activity for adult education on their part. With regard to institutional support, there was broad consensus that Botswana possesses already an admirable structure for training and institutional assistance in the Department of Adult Education.
\end{abstract}

\section{Keywords}

Adult Education, Professional Associations, Employment Situation, Adult Learning Programs 


\section{Introduction}

The issue of relevance and match between university training and the needs of industry becomes critical in today's competitive world. Achieving high quality in adult learning programmes depends in large measure on the availability of knowledgeable, skilful, sensitive and socially committed adult educators (Youngman, 2005: p. 6). To operate as professionals, practitioners in a field of endeavour like adult education need to draw on a reliable knowledge base and to feel confident that their services are grounded in a set of skills and understandingsdeveloped in a good part through their professional academic training - that others do not have. Oduaran and Modise (2009) state that "in many nations, adult education is being urgently asked to specify ways and means by which it seeks to enhance directly the total living, productive and competitive capacities of its target audience" (p. 273). Reinforcing this position, Obasi (2014: p. 27) argues that "Adult education as a field of study is indispensable in national development as its relevance cuts across all Sectors". It is imperative therefore, that adult education through research studies such as this one justifies its position as a possible partner in economic, social and human development (UNESCO, 2009; Popovic, 2010). Obasi (2014) observes that "adult learning and education is now more than ever emerging as an empowering tool capable of liberating and harnessing the creative forces of people, the potential of communities and the wealth of nations in a situation of global crisis" (p. 28. citing Ouane, 2009). These sentiments are underscored by Talabi (2014) who observes that "the trend in the academia for multi-disciplinarity is one which augurs well for Adult Education as an academic enterprise. The discipline by its theories, principle and practice, being highly interdisciplinary, is gradually being recognized that it has something to offer in the economy and relevant to the societal human capital development” (p. 105). These opinions that identify adult education as playing a very critical role in society underscore the significance of recognising adult education as a profession.

Any field needs qualified leadership in order to develop, particularly one like adult education that is spread across so many other sectors. There must be someone with the requisite skill, knowledge and experience to stimulate design of programs, mobilization of clients, recruitment of staff, allocation of resources and implementation of policy. The question then is, "where do those leaders get their competencies and knowledge?" Some of those attributes are learned on the job, a long-standing pattern in adult education. But in most fields of endeavour or technical work, there has been over the last 150 - 200 years in industrialized countries a process of "professionalisation" to ensure and promote an adequate supply of competent technicians and leaders to ensure that these people get the respect and remuneration they deserve.

Although this study is focused on the unique characteristics of DAE at the University of Botswana, it made links to external factors. External influences also play a larger factor in monitoring the course and direction of a profession; hence the study also involved other external forces like Botswana Adult Education Association. External here simply means the third mission (community engagement) which encourages institutions to work with others outside the four walls of the University. This is significant because like all institutions, the Department of Adult Education's effectiveness is determined by the effectiveness of its graduates in the labour market.

This paper briefly outlines the history of the Department of Adult Education. Secondly, it discusses the profession of adult education from literature as a means of conceptualising the theoretical framework, discusses the methodology employed for the study, presents and discusses the findings. The paper concludes that the web of alumni of UB training cycles creates at present the closest thing to a broad professional association available and its own infrastructure the best estimate of amenities for continuing professional education. Stakeholders agreed that professional associations are currently weak in Botswana and made propositions for more passionate activity on their part.

\section{Context of the Study}

The history of the Department of Adult Education is closely related with that of the University of Botswana (UB). The higher education needs of Botswana were originally served by the inter-territorial and non-denominational University of Basutoland, Bechuanaland and Swaziland (UBBS) established by the British Government in 1964. Thus university was a successor institution to Pius XII College, a Catholic University College founded in 1945 and based in Roma, Basutoland (today's Lesotho). This institution was renamed University of Botswana, Lesotho and Swaziland (UBLS) in 1966, in preparation for the independence and subsequent name changes of two of the member countries. After Lesotho, which had gained independence in 1968, withdrew from the system in 1975 and nationalized most of its faculties, the other countries operated a two-campus University of Botswana 
and Swaziland (UBS) from 1976 to 1982, and started developing their own full-fledged institutions. Thus the University of Botswana (UB) was born in 1982 (Booth, 2003). Prior to this date, however, the tradition of extramural and extension education for adults had nonetheless been firmly established in Botswana.

On the heels of independence, the new nation launched with UNESCO's assistance a major distance education initiative to provide in-service training to primary school teachers, the Francistown Teacher Training Project. It led in turn to the creation of the Botswana Extension College in 1973, soon to be incorporated into the national Ministry of Education, with the "the mandate to provide secondary school courses, upgrading and retraining courses, and information courses not leading to exams" and to do so through " 'three-way teaching,' involving correspondence courses, radio programs, and face-to-face methods” (Dodd \& Youngman, 2001). At the same time the Division of Extramural Services within the Botswana branch of UBLS tended to outreach training and education leading to degrees and in 1978 it was transformed into an "Institute for Adult Education" in the UBLS Faculty of Education, which preserved a Centre for Adult Education and Extension Services. The new Institute of Adult Education was the first one to turn its attention to the professional training programs for adult educators. Needs in this area were considerable, given that Botswana had recently affirmed the centrality of adult education to its development and yet had few trained practitioners. It was in 1977 that the National Commission on Education gave emphasis and priority to adult literacy and related it to the development of Botswana. The new government policy, the National Policy on Education of 1977, which was the result of the Commission's work categorically stated that literacy work be given the status it deserved in the nation's educational plans and policies. The result of this policy was the establishment of the Department of Non-Formal Education (DNFE) in 1978 (Nyirenda, 1997: p. 8). The first major activity of the Government Ministry, DNFE, was in fact to launch an ambitious National Literacy Program in 1980.

The Institute for Adult Education, for its part, began in 1979 to offer the Diploma in Adult Education, a two-year full-time program of professional studies at the diploma level. Four years thereafter, in 1984, under the aegis of the newly created University of Botswana, a second program of part-time studies was created at the "Certificate" level and offered by distance education for in-service government employees who had professional experience and held the Junior Certificate (the equivalent of 10 years of schooling). It was likewise a two-year program but applicants were only accepted on alternate years. The Certificate program continued to be offered for seventeen years thereafter. A Bachelor's degree program with biennial recruitment was added in 1986 and switched to annual recruitment in 1990. The following year, the Institute of Adult Education split into two new entities: a Department of Adult Education, responsible for academic training of adult educators and housed within the UB Faculty of Education; and a Centre for Continuing Education, which assumed the extension and public education functions of the former IAE and became a University-wide outreach facility. A Masters program was created in 1995 by the Department of Adult Education and, in 2000, a M.Phil./PhD program was established as well.

\subsection{Theoretical Framework}

There have been numerous and conflicting debates about whether or not adult education should professionalize or not. Over the years, scholars and practitioners at both national and international levels have had intense debates on issues relating to adult education as a field of study and practice (Obasi, 2014: p. 28 citing Mera 2004). Literature depicts that the "the need to recognise adult educators as professionals has been emphasised on several occasions” (Lima et al. 1988; Pinto, Matos, \& Rothes, 1998; Guimarães, Silva and Sancho, 1988 cited in Jääger and Irons (2006: p. 25). This need is a result of the lack of recognition and poor public image of adult education in many societies. Jaager and Irons (2006: p. 25) further observe that "this lack is still a fact and it affects many professionals not only in terms of professional relationships with organisations in which these practitioners are working, but also due to their profile and material conditions which have a considerable impact on difficulties in there cognition of individual competences and in finding reference frames for occupations skills". The term "profession" has evoked a lot of debate in social service fields like adult education. Historically, high-profile trades like medicine, law and architecture have been the first to professionalise. Analysts of the process (Etzioni, 1969; Freidson, 2001) often cite in one form or another three characteristics that are generally required for a field to professionalise: a body of technical knowledge; a network of institutional support (particularly professional associations and university linkages for training); and some means of controlling entry or regulating supply and demand in the labour market. 
Professionals, Borgatta \& Montgomery (2000: p. 2260) point out, are assumed to be "experts with abstract, esoteric knowledge and skills that set them apart from others"-not just the general public, but practitioners in other fields as well. If they do not offer their clients specialised resources not available from others, then there is little justification for their status. Maintaining that privileged role depends on having a demonstrable "knowledge base"- $\mathrm{a}$ set of findings, of proven technique and accumulated lessons of practice that accrues from experience and experimentation in the field and constitutes specialized knowledge. Lee Shulman (1997: p. 254) presents the linkage between knowledge base, university and practice succinctly:

To call something a profession is to claim that it has a knowledge base in the academy broadly construed. It has research and theories. Therefore, professions change not only because rules of practice change, or circumstances change, or policies change, but because the process of knowledge growth, criticism, and development in the academy leads to the achievement of new understandings, new perspectives, or new ways of interpreting the world.

This change in professions presented above does not necessarily signify that the notion of a knowledge base loses all importance in social science professions, but rather that it changes meaning in several interesting ways:

1) First, professionals put as much emphasis on process as on product-that is, on skill in relating to clients and tailoring services to specific contextual need rather than on the validity of a hard body of technique constituted ex ante (e.g. Schein, 1969, 1999). Interestingly, adult educators in particular tend to stress the "process" dimensions of their work: knowing how to facilitate learning by others and sense their development needs rather than to apply tried-and-true formulas to every case.

2) Second, emphasis is put as much on the deliberative capacities of the body of professionals and their associations as on the singular judgments rendered by individual experts. That counts-in this view-is less the formulas that can be applied in a broad range of cases than the ability of professionals to reason about appropriate interventions, to call on a network of colleagues and backstopping institutions that can adjudicate best practice and to constitute in this way credible “communities of practice” (Shulman, 1997; Orrill, 1997).

3) Third, increased importance is given as well to means for associating practitioners and clients in the adaptation and development of the knowledge base, through suchpractices as participatory action research (Imel, Brockett \& James, 2000; Fueyo \& Koorland, 1997). Imel et al. conclude that academic institutions charged with research in fields like adult education would do well to open the debate about the knowledge base to new perspectives and forgotten voices, "allowing for a timely sharing of new knowledge, by voices that reflect the entire spectrum of thought and action” (p. 267).

Meanings and approaches therefore change, but the notion of a knowledge base retains much of its importance for human service professions like adult education. It is inconceivable, however, without the next element in the triad of requisite conditions for professionalization: dense and supportive institutional networks.

Professional associations have been a historical support in the consolidation of new work specialties and the assertion of their privileges. Along with the academic research institutions that back them up, associations serve to legitimize the social roles and titles of professionals, as Raber (1997) details in the case of librarians and their associations. They make public the debate about best practice, lobby for greater recognition in law and public policy and defend the interests of practitioners. The European Commission (2010: p. 103) observed that "these associations can defend the rights of the professional group, exchange knowledge, build up a common understanding of what defines the profession as such, and develop as a learning community or community of practice”.

The topic of professional associations in adult education continues to stimulate much debate, centred in particular on the question of whether these associations are effective organs, and inclusive of all constituents. Brockett (1989: p. 122) argues that the "confusion over the role and scope of such associations as well as the debate within the field over the issue of professionalization has often diminished the influence of these associations.” Merriam \& Brockett (1997) acknowledge the important role played by these associations but lament the fact that they are not fully representative of adult educators. One dilemma facing the adult education sector is that it is very diverse and "interwoven with other sectors" (European Commission, 2010: p. 98). This diversity can be seen in the various target groups of adult learning subjects covered by adult learning courses. They can also be seen in the professional pathways to becoming an adult learning professional, the employment situation of adult learning professionals and furthermore, in the competences required for working in this sector. This diversity makes it difficult to develop the sector as a whole and in particular a dedicated profession” (Ibid. (p. 17). It is not surprising therefore, that adult education professionals are found working in all sectors of the economy. 
Hence, "Adult education as a multidisciplinary field overlaps with many subject areas. It includes basic and continuing education, vocational and technical education, higher education and professional development, it is offered through formal, non-formal and informal means and by a variety of actors. These actors have diverse experiences and function from divergent notions of what the purpose of adult education is” (Obasi, 2014: p. 28).

\subsection{Problem Statement}

Despite progress made so far in developing adult education in Botswana, there is still lack of understanding of what constitutes adult education as a profession. For example, more often than not people equate adult education to adult literacy. A current debate here in Botswana relates to the place of community development in adult education. In some quarters the argument is that community development cannot be part of adult education. The name of the programme is seen to be itself contributing to the confusion, what is adult education? This question has appeared in literature and does not have a single answer because of the heterogeneity of the context of adult education. As a result of the current image of adult education, especially as offered by the DAE, UB, it has become imperative that the department wishes to have a name change that will capture the major focus of the DAE's offerings. Based on this background, the researcher found it necessary to explore perceptions of the DAE graduates in relation to what they believe the department have to qualify as an adult education profession.

\subsection{Purpose of the Study}

The purpose of this study was to find out the perceptions of adult education professionals in Botswana about what they believe would constitute effective professions of adult education.

\subsection{Significance of the Study}

The study has both theoretical and practical implications. It contributes to the body of knowledge of adult education, particularly in the African context where the subject of training of adult educators is receiving great attention, and it also provides feedback to programme staff. Stakeholders can use feedback for curriculum development and improvement to suit labour market needs. The study will assist in pointing to what is lacking in order to be recognised as a full profession. It would also be necessary for the DAE to take heed of the study findings to improve its public image. Furthermore, it will inform potential students of DAE about the status of adult education as a profession in Botswana. A positive image will serve as a marketing strategy while a negative picture will prompt the DAE to work towards improving their image.

\section{Basic Research Design}

A qualitative method was used to generate data and stakeholder perspectives concerning the status of the knowledge base on which they draw. This was done through targeted interviews with key informants selected from among the graduates and stakeholders external to the program representing civil society and employer organizations. The next stage was to submit the insights gained from these for discussion by focus groups composed of "internal" as well as "external" stakeholders of the program in order to solicit their further impressions and obtain their assistance in interpreting the results. As McMillan points out, the use of "multiple forms of data collection for the same study provides greater depth” (2000: p. 269).

\subsection{Interviews}

Selection of the individuals interviewed was carried out through elite sampling techniques. Preliminary discussions were held with stakeholders to identify, through cross-reference and snowballing, candidate individuals who appear to have both the deep level of familiarity with the issues and the potential interest in the research that is required to serve as key informants. Overall, eight were picked and interviewed: at least one from each of the groups named plus four additional individuals who seemed particularly well placed and knowledgeable to take part or helped to better represent the diversity in one or another of the subgroups in question.

\subsection{Focus Groups}

The second data collection method was focus group discussions. The purpose of holding focus group discussions 
was to seek explanations for patterns that have been observed in the interview data and to address questions that could not be adequately addressed with that information. A one day workshop was held with four focus groups comprised of selected graduates of the Diploma, Bachelor's and Master's programs which fed back the whole workshop for further discussion. Each focus group comprised of eight participants. An important criterion of selection was demonstrated ability to dialogue with people having different experiences in addition to knowledge of issues and ease of articulation.

\subsection{Data Analysis}

Results of key informant interviews and focus group were analysed both internally and cross-sectionally. In other words, careful re-reading and examination of transcripts brought out central themes and illuminating explanations or descriptions as well as the subtext of frequently used terms, analogies and references. The tape-recorded interviews were transcribed soon after, when the interviews were still fresh in the researcher's mind. A verbatim transcription of the entire process was carried out to ensure familiarity with the data. Everything was transcribed and reduction of data by eliminating the ones that were not relevant was done during analysis. The qualitative data analysis process involved coding the data collected from interviews and focus groups. The interviewees were given pseudonyms for purposes of anonymity. The strategy for coding involved assigning appropriate codes to the data on the basis of their relatedness to the research questions. McMillan (2000: p. 264) states that "the first step in data analysis is to organize the data, separating it into workable units, while looking for categories and concepts, topics and themes." After identifying sets of similar information throughout the data, each set of data was placed under a theme that best describes the data set as a category. At this stage of data analysis the researcher looked "for relationships among the categories and patterns that may suggest generalizations” (McMillan, 2000: p. 265).

\section{Findings}

This section reports findings drawn from interviews with key informants, and focus group discussions-elicited to address key issues. It is dedicated to critical dimensions of adult education professionalization in Botswana: the consolidation of a knowledge base, the development of professional associations and the reinforcement of institutional support.

\subsection{A Firm Knowledge Base in Adult Education}

To operate as professionals, practitioners in a field of practice like adult education need to draw on a reliable knowledge base. They also need to feel confident that their services are grounded in a set of skills and understandings - developed in good part through their professional academic training - that others do not have. These issues were probed with key informant interviews and focus groups. They discussed the areas of knowledge and skill that they felt were most useful on the job and those in which they thought new entrants to the field should be most strongly prepared.

For most part, key informants and focus groups participants-perhaps with perceptiveness to the future-tended to emphasize the foundational, human relations and new technology aspects of the knowledge base, for example, an interviewee from the Department of Adult Education suggested that graduates need to have

Social, economic and political awareness and an understanding of the wider context within which they operate. We have to know about sociology, critical analysis of policy in the society, human rights, technical jobs, [and] how to develop programs.

A graduate interviewee working in the government sector felt that the multidisciplinary nature of the field is in itself important in that

People with [such a] background can fit in any sector, whether it is the engineering sector, the health sector, and so forth, because it is about being able to package information in a manner that could then be disseminated and easily understood, and being able to diagnose what the learning needs are, and the ability to also evaluate performance...

And an interviewee from the Botswana Adult Education Association (BAEA) weighed in with arguments in 
favour of professionals who are well enough trained to present convincing visions of the future and are themselves personally "empowered":

I do not think properly trained adult educators should be...conveyors of development information but rather...change agents, in other words they should be the type of people who should work with communities to paint pictures that would help the community see [that something is] wrong with the current system where people are expected to just lay back and wait for government to seek them out...to be...part of the destitute policy...[T] hat kind of agent is not the one that we have on the ground right now...I want us to train the kind of adult educator and extension worker who would be able to know that they have so much power, because if they are not empowered themselves, I do not think they can empower anybody.

\subsubsection{Comparison of Interviewees and Focus Groups Viewpoints}

The concern for foundations understandings, technical prowess and group development skills is likewise evident when one compares the themes stressed by the two different sets of qualitative discussants: the key informant interviewees and focus group members. This summary portrayal is offered in Figure 1 below in the form of a diagram where the overlap represents themes common to the groups.

The six items listed in the overlapping area-foundational areas like Sociology and Psychology, skills in research and group development capacities like teamwork, group dynamics and understandings of human rights-represent a forward-looking agenda evidently grounded in stakeholders' views of future needs for adult education in Botswana.

Significantly, when the lens is narrowed to a focus on skills required of adult educators in current Botswana development, strongest emphasis is placed by the interviewees and the focus group participants on interactive, participatory and group dynamics competencies - with an important secondary one on brainstorming and critical thinking skills-while the two areas that constitute the common denominator between the groups' respective viewpoints are communication skills and teamwork. This inventory is pictured in Figure 2 below. Focus groups generated a long list and this may be explained by the fact that they had the opportunity to brainstorm as a group.

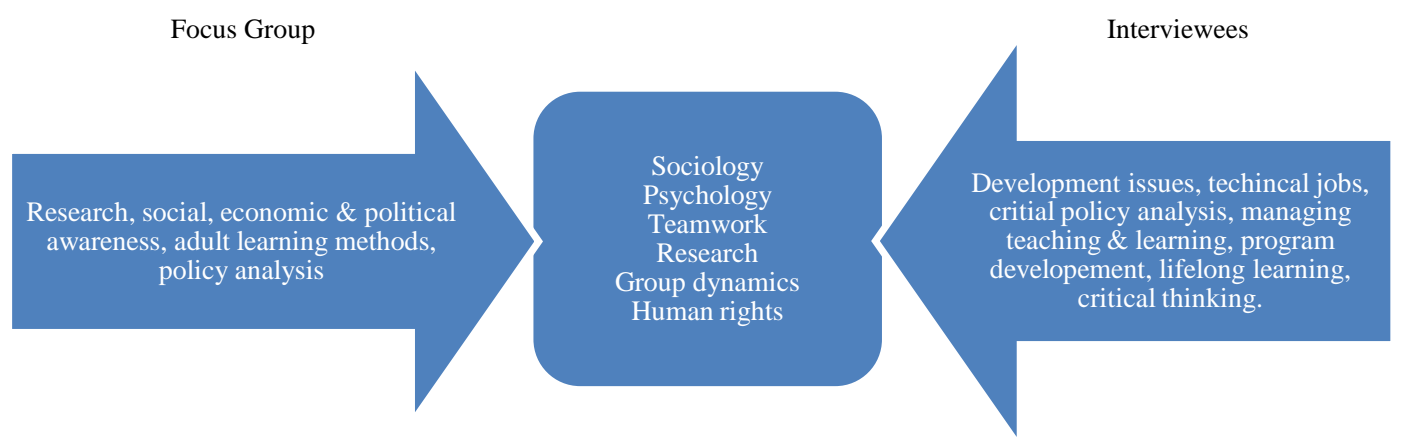

Figure 1. Diagram of knowledge areas stressed by focus groups and interviewees.

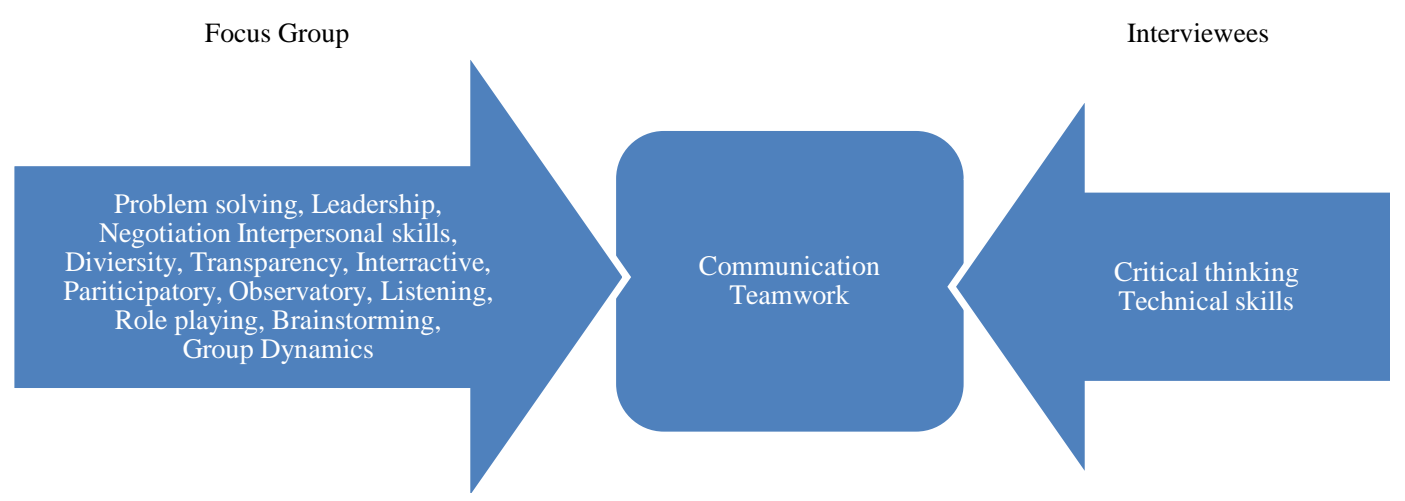

Figure 2. Diagram of skills required of adult educators. 
The views of interviewees represented in the above chart came in the form of suggestions such as the following from the faculty interviewee:

There are a range of technical skills areas; research is one, which people need to know about, development work is going to demand some kind of skills (DAE staff Interviewee).

One interviewee working in the government sector expanded on the ability to communicate, to understand the dynamics of communication, like group dynamics.

Those of us who have at least had an appreciation of group dynamics...each time you go into a meeting and just sit back to see what is going on...you can see a lot of interesting things. And yet, most of us who are facilitating the meeting are missing on those dynamics.

\subsubsection{DAE Offerings and Needs in the Labour Market}

Similar results emerged when stakeholders were asked what types of adult education-related skill and knowledge were most in demand in the labour market. The knowledge areas identified as being in high demand for training and extension work in both rural and urban areas of Botswana are pictured in Figure 3 below.

The overlap represented by the middle box once again delineates points - and in this case, types of knowledge - cited by both of the overlapping groups. Both groups cited the need for foundational understating of psychology, or research methodology and of group dynamics as key areas of knowledge for adult education practitioners that are in high demand.

Skill areas given most emphasis as high demand on the labour market by these same groups are pictured in Figure 4 below.

Though the specifications of areas are more similar here from group to group-a strong common thread nonetheless seems to unite the observations, and it has to do with communication, group development and research. An expressive minority also emphasized the importance of skills related to the preservation of indigenous knowledge: the ability to recognize it, to elicit it, to involve local craftspeople and elders in recording it, etc. As a graduate interviewee working in the NGO sector remarked,

Our indigenous knowledge needs to be resourced somewhere. Adult education students need to be taught how to capture this so that at the end of the day we will be having professional people who will articulate the indigenous knowledge.

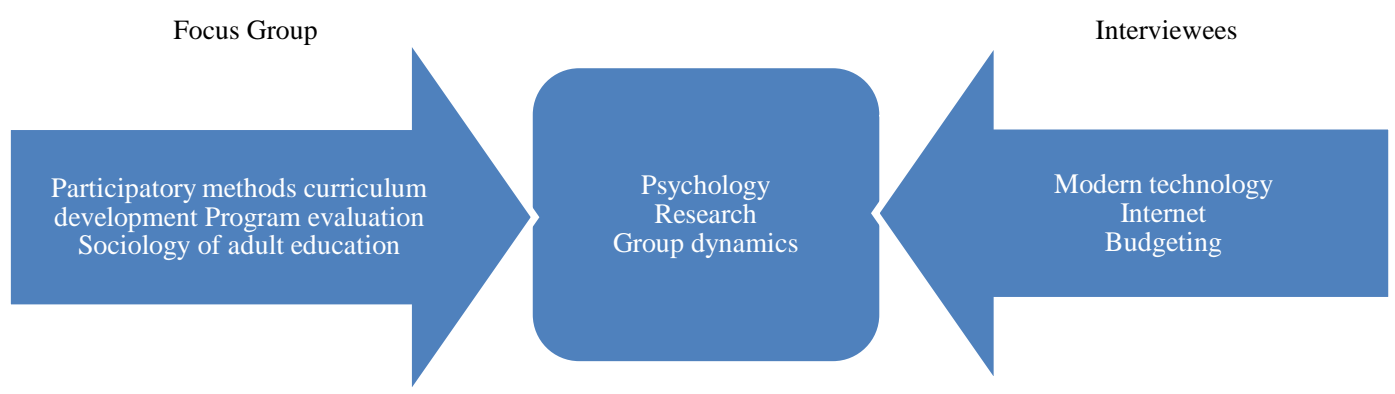

Figure 3. Diagram of knowledge areas most in demand for training and extension work.

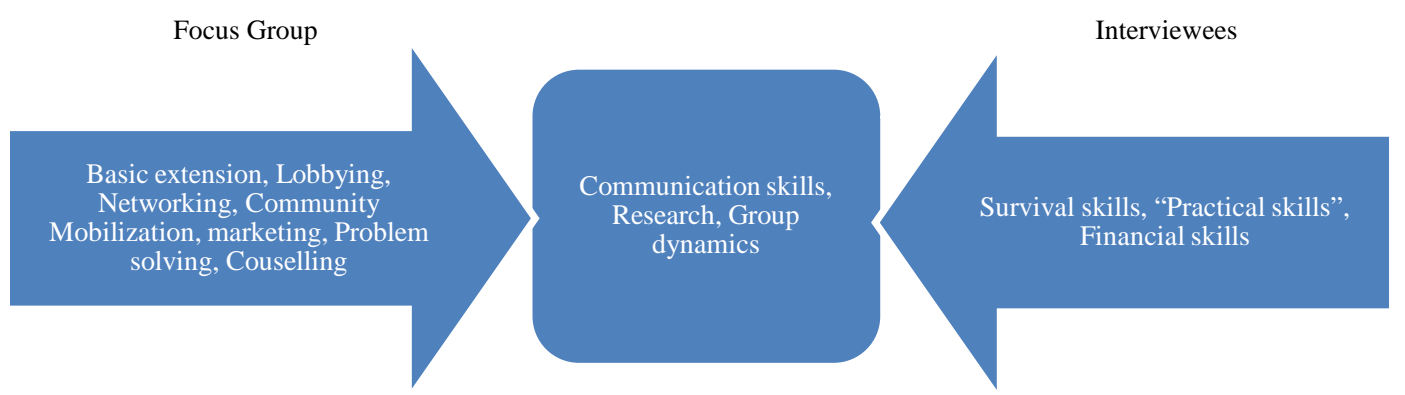

Figure 4. Diagram on skill areas emphasized as in high demand on the labour market. 
Others of the comments made by stake holders about critical skills are also revealing. For example, an interviewee from the public sector remarked that no one now escapes reliance on computer technology.

This is the way the world is going. So functional literacy in the use of these things is important. Now we have the Internet [and] Internet cafes are mushrooming.

Several others emphasized the theme of "multi-skilling" or the necessity of adult education professionals having skills relevant to more than one sector, sometimes suggesting that it was their vocation to provide a sort of "glue" in rural community development. An interviewee from the public sector took the example of the training required by conservation efforts:

Natural resource projects are usually multi-sectoral, so the best graduates that one would expect out of the adult education programs would be the ones that are also multi-disciplinary.

\subsection{Strengthening the Knowledge Base}

The two stakeholder groups formulated a number of suggestions they consider to be viable options for strengthening the knowledge base of adult education in Botswana. These suggestions include the development of research and publications as well as the dissemination of the knowledge generated by the research; the creation of strategic linkages involving all facilitating agencies; and the conduct of employer surveys. Several citations from the interviews and focus groups provided below give a sense of the range of stakeholder views.

A faculty interviewee spoke of a study of HIV/AIDS that had been done by program faculty in which the adult education dimensions of the problem were clearly delineated, but that had never been properly disseminated. The speaker concluded that

We may be missing out on an opportunity to demonstrate that a lot of socio-economic issues have [an] adult education background which we should address.

A community based organization interviewee spoke of the importance of dissemination among the subjects of research themselves.

In the past I used to tease some of my friends at UB [by telling] them that it is a pity that our University is like $[a n]$ island....[W] e...see researchers coming from UB to...test the knowledge of the people and...[then they] go away with it and...never bring anything back. I [told them], "You need to do your applied research.... with people, [bring back] the results, let them know what you are doing and [its] outcome. If you disseminate the information back to them they will [understand] and they will quote you every time [the issue] crops up."

Many of the stakeholders emphasized the need to study the market potential and opportunities of the program. One insisted that we need to have

more research, more people [looking] into the demand, the trends, the different target groups [for the program], the labour market [for its graduates]...[We should seek] means of actually building capacity of some of the structures and institutions that are already on the ground that could actually uptake these in their own right, working hand in hand with the university (Interviewee from NGO).

The structures and institutions to which he was referring include the government sector, the private sector, NGOs, and community-based organizations. He is arguing that closer collaboration with these entities would enable the Department of Adult Education to make a better fit between its trainees and the context in which they would work.

\subsection{Professional Associations}

Another characteristic of professions according to the literature is the existence of associations that bring practitioners together in defence of their own interests and in furtherance of their craft. There is relatively little resource of this nature in Botswana at present, despite the existence of a Botswana Adult Education Association, which has sponsored a number of national events and been represented in international for a but has essentially been inactive for a number of years as far as promoting affiliation and involvement among practitioners is concerned. That is not to say that there is any lack of desire to professionalize or of aspirations to a higher level of 
association and expertise.

A graduate of the program took this viewpoint further in the direction of association by suggesting that the professionals in the field of adult education should

draw up a code of conduct [and establish] a governing body that would screen...applicants [to the profession] for [a] practicing certificate [licence to practice].

And an interviewee from the Botswana Adult Education Association also suggested that the BAEA could play a role:

I think the association can help the department [by determining] who really is dealing with adult education out there, so that we deal with people as an association, get as much information about their activities [as possible] and so on.

None of the stakeholders contacted, though, expressed any of the qualms sometimes associated with professionalization and mentioned in the literature: namely, the concern that excessive emphasis on licensing and restricting the occupation of adult educator to those with a particular set of credentials would deprive the field of some of its richness and human resources. In the United States, for example, this reservation has been frequently expressed in adult education, which is sometimes regarded as either the tail end of traditional professionalization or the vanguard of a new wave (Easton \& Crew, 1992); and it has been feared that overly restricting the profession would cut off the ability of many varied practitioners to operate as adult educators and so short-circuit an essential reflex of lifelong learning.

A representative of the private sector underlined some of the other advantages that a strong association can confer:

Apart from extending knowledge, associations can be used to evaluate the qualifications that people have and accredit them at different levels and help people to aspire to higher levels within that association. I can give the example of the Institute of Management, depending on how many years you have been a practitioner, and what qualification you have, you can go in as an associate, a member or a fellow. You can work your way up [and become] a fellow [who] is experienced and has got a lot of knowledge as a practitioner in that field. If we did that it can help us as well.

But all seemed to recognize that few of these facilities are available at present.

\subsection{Continuing Education}

The third leg of professionalization is dedicated to facilities for professional training and related institutional support. Botswana is obviously fortunate to be one of the few African countries with a strong University-level Department of Adult Education, granting several different programs and rich with 25 years of experience. It already has one means of continuing professional education in that a certain proportion of those taking lower qualifications return after a period in the field to seek higher qualification. But conditions for maintaining knowledge and skills and keeping abreast of new developments while in the field are not ideal. These issues were addressed in the key informant interviews and focus group discussions in order to see what stakeholders felt about the existing resources for continuing education and priorities for upgrading them.

The stakeholders suggested that there were a number of different ways that could be used by aspiring adult educators to keep abreast of new knowledge and skills. One way was through internships, training, and in-service programs offered by allied departments of the University of Botswana. Sample views of the various stakeholders are presented below.

An interviewee from the government sector felt that the Department of Adult Education should be able to recruit other branches of the University to assist with the task:

You do not even have to limit [the training work] to the DAE lecturers. Broaden it...[to include] lecturers from the Department of Business, for example, [or] even from the [relevant] technology field, and let them talk [about] how technology could enhance development, how technology could be taken to remote areas with less cost and how it could turn things around. Then this course can actually become more interesting.

Focus groups indicated that in-service training and professional meetings were the kind of support most 
needed to help graduates excel in their jobs and to demonstrate the importance of their services. One of them advised:

Have in-service training when there is new knowledge to be shared. The world is changing very fast, therefore officers should not [wait] long before they [undertake] the next training (Focus group participant).

There was broad consensus that Botswana possesses already an admirable structure for training and institutional assistance in the Department of Adult Education but that its provisions for the continuing education of practitioners could be usefully upgraded. Most felt that prospects for continuing education while in the field are not ideal, several means could be explored to support the in-service learning of practitioners. These include internships, seminars, and sensitizing senior management in employing organizations about the value-added benefits of adult education.

\section{Conclusion}

This paper has focused on the key issue of professionalization of adult education careers in Botswana. The emphasis and the comments seemed to betray at the same time a concern that adult educators acquire a set of "flexible" skills that would allow them to adapt to a changing employment situation and to develop new venues for adult education in varied institutional and sectoral settings. In fact, when comments about present weaknesses of professional associations and potentials of the University are put side by side, it becomes evident that the network of alumni of UB training cycles constitutes at present the closest thing to a broad professional association available and its own infrastructure the best approximation of facilities for continuing professional education. Stakeholders concurred that professional associations are currently weak in Botswana and made propositions for more passionate activity on their part.

\section{Acknowledgements}

A major part of this paper has been adapted from my Ph.D. dissertation entitled: Labor Market Demand and Incipient Professionalization in African Adult education: Tracing Graduates of University of Botswana Adult Education Programs.

\section{References}

Booth, M. Z. (2003). Settler, Missionary, and the State: Contradictions in the Formulation of Educational Policy in Colonial Swaziland. History of Education, 32, 35-56. http://dx.doi.org/10.1080/0046760022000032404

Borgatta, E. F., \& Montgomery, R. J. V. (2000). Encyclopedia of Sociology (2nd ed.). New York: Macmillan.

Brockett, R. G. (1989). Professional Associations of Adult and Continuing Education. In S. B. Merriam, \& P. M. Cunningham (Eds.), Handbook of Adult and Continuing Education (pp. 112-123). San Francisco, CA: Jossey-Bass.

Dodds, T., \& Youngman, F. (1994). Distance Education in Botswana: Progress and Prospects. International Journal of E-Learning \& Distance Education/La Revue internationale de l'apprentissage en ligne et de l'enseignement a distance, 9, 61-79. http://cade.athabascau.ca/vol9.1/dodds-youngman.html

Etzioni, A. (1969). The Semi-Professions and Their Organization: Teachers, Nurses, Social Workers. New York: Free Press. European Commission (EC) (2010). New Skills for New Jobs: Action Now. Report by the Expert Group, Feb. Brussels.

Freidson, E. (2001). Professionalism: The Third Logic. Chicago, IL: The University of Chicago Press.

Fueyo, V., \& Koorkland, M. A. (1997). Teacher as Researcher: A Synonym for Professionalism. Journal of Teacher Education, 48, 336-344. http://dx.doi.org/10.1177/0022487197048005003

Guimarães, P., Silva, O. S., \& Sancho, A. V. (2000). A educação/formação de adultosnasassociações: iniciativas popular mente promo vidasousocialmente or ganizadas? In L. C. Lima (Org.), Educação de Adultos (pp. 169-236). Forum II. Braga: Universidade do Minho/Unidade de Educação de Adultos.

Imel, S. Brockett, R. G., \& James, W. B. (2000). Defining the Profession: A Critical Appraisal. In A. L. Wilson \& E. R. Hayes. (Eds.), Handbook of adult and continuing education: New Edition (pp. 628-642). San Francisco, CA: Jossey-Bass.

Jääger, T., \& Irons, J. (Eds.). (2006). Towards Becoming a Good Adult Educator. AGADE Project. http://www.nordvux.net/download/1740/manual_for_adulteducation_prac.pdf

Lima, L. C. et al. (1988). Documentos Preparatórios III. Reorganização do Subsistema de Educação de Adultos. Lisboa: Ministério da Educação/Comissão de Reformado Sistema Educativo. 
Mcmillan, J. H. (2000). Educational Research: Fundamentals for the Consumer. New York: Addison Wesley Longman Inc.

Merriam, S. B., \& Brockett, R. G. (1997). The Profession and Practice of Adult Education: An Introduction. San Francisco, CA: Jossey-Bass.

Nyirenda, J. E. (1997). A Study into Collaboration for Increasing Coverage of the Provision of Adult Literacy in Botswana: A Research Report. http://www.adeanet.org/wgnfe/publications/nyirenda.html

Obasi, S. (2014). Adult Education in Nigeria: A Discipline in Search of Scope and Direction? Journal of Education and Practice, 5, 27-31.

Oduaran, A., \& Modise, O. M. (2009). Relevance, Equivalence and Progression in an Adult Basic Education Curriculum for Botswana. The Western Journal of Black Studies, 33, 273-281.

Orrill, R. (1997). Pragmatism, Scientific Method. Journal of the British Society for Phenomenology. New York: College Board Publications. 27.

Pinto, J. (Coord.), Matos, L., \& Rothes, L. (1998). Relatório do Estudo de Avaliação do Ensino Recorrente. Lisboa: Ministério da Educação/Secretaria de Estado da Educação e Inovação. (Unpublished Document)

Popovic, K. (2010). CONFINTEA VI: Adult Education and Learning-From Rhetoric to Action, European Infonet Adult education. http://www.infonet-ae.eu/en/articles/confintea-vi-adult-education-and-learning-from-rhetoric-to-action-0866

Raber, D. (1997). Librarianship and Legitimacy: The Ideology of the Public Library Inquiry. Westport, CT \& London: Westwood Press.

Schein, E. (1969) Process Consultation: Its Role in Organization Development. Reading, MA: Addison-Wesley Publications.

Schein, E. (1999) Process Consultation Revisited: Building the Helping Relationship. Reading, MA: Addison-Wesley Publications.

Shulman, L. E. (1997). Professing the Liberal Arts. In R. Orril (Ed.), Education and Democracy: Reimagining Liberal Learning in America (pp. 151-173). New York: The College Board.

Talabi, A. S. (2014). Adult Education: Discipline Still in Search of Definition, Focus, Recognition and Patronage in Nigerian Society. Journal of Arts and Humanities (JAH), 3, 99-107.

UNESCO (2009) Living and Learning for a Viable Future: The Power of Adult Learning. 6th International Conference on Adult Education, Belém, 1-4 December 2009, 7 p.

Youngman, F. (2005). Making a Difference: Development Agendas and the Training of Adult Educators. The Training of Adult of Adult Educators In Africa and Asia/Pacific: Present Situation and Recommendations for the Future. Key Note Address at the Conference Organized by the Institute for International Cooperation of the German Adult Education Association, Cape Town, 11-13 May 2005. 